\title{
Formação de professores no Curso de Pedagogia da UFBA e a atuação docente na perspectiva inclusiva
}

\author{
Sheila de Quadros Uzêdal \\ Regiane da Silva Barbosa²
}

\section{RESUMO}

O presente artigo resulta de uma pesquisa realizada por meio de estudo descritivo de caráter qualitativo que tem como objetivo discutir a formação de professores no curso de pedagogia da UFBA para atuar com estudantes público-alvo da educação especial (PAEE). A pesquisa foi realizada considerando a grade curricular do curso e a opinião de estudantes sobre o tema, obtida a partir da aplicação de questionário. As respostas foram organizadas em categorias e demonstram que os estudantes em formação consideram que a inclusão escolar é relevante, mas para efetivá-la é necessário investir em formação de qualidade e a concentração do tema em poucos componentes curriculares não contribui com o preparo desses profissionais. Diante disso, os estudantes pontuaram a necessidade de oferta de mais componentes e/ou a transversalização do tema na grade curricular, além de oportunidades de relacionar teoria e prática por meio de estágios na área, o que diminuiria a sensação de despreparo e medo, apontadas pelos participantes da pesquisa e também por professores que atuam em escolas de educação básica, como demonstram outros estudos sobre o tema. Evidencia-se a necessidade de repensarmos a formação de professores pedagogos, preparando-os para atuar e consolidar a inclusão escolar.

Palavras-chave: Formação de Professores. Graduandos em Pedagogia. Inclusão Escolar.

\section{Teacher Education in UFBA Pedagogy Course and teacher's practice in the} inclusive perspective

\begin{abstract}
This article results from a research carried out through qualitative descriptive study and aims to discuss the teachers' initial education in the Pedagogy Course of UFBA to work with especial education students. The research was performed considering

1 Doutora em Educação. Universidade Federal da Bahia. Salvador, Bahia, Brasil. Orcid iD: http://orcid.org/0000-0003-4549-0800. E-mail: sheilauzeda@ufba.br

2 Doutora em Educação Especial. Universidade Federal da Bahia. Salvador, Bahia, Brasil. Orcid iD: http://orcid.org/0000-0002-0305-902X. E-mail: regiane.barbosa@ufba.br
\end{abstract}


the curriculum of the course and the opinion of students on the topic, collected through the application of a questionnaire. The answers were organized into categories and demonstrate that students in initial education consider that school inclusion is relevant, but that to make it effective, it is necessary to invest in the education quality offered in the course and the concentration of the topic in a few components of the curriculum does not contribute to the preparation of these professionals. In view of this, the students pointed out the need to offer more components, and/or the transversalization of the theme in the curriculum, in addition to opportunities to relate theory and practice through practicum experiences in the area, which would reduce the feeling of unpreparedness and fear, pointed out by the research participants and also by teachers who work in basic education school, as shown by other studies on the subject. It Highlights the need to rethink the initial teacher education, educating them to work and consolidate school inclusion.

Keywords: Teacher Education. Graduating in Pedagogy. School Inclusion.

\section{Formación de profesores en el curso de pedagogía de la UFBA y su actuación en la perspectiva inclusiva}

\section{RESUMEN}

Este artículo es el resultado de una investigación llevada a cabo a través de un estudio descriptivo cualitativo y tiene como objetivo discutir la capacitación de maestros en el curso de pedagogía de la UFBA para trabajar con estudiantes de la educación especial. La investigación se realizó considerando el currículum del curso y la opinión de los alumnos sobre el tema, obtenida de la aplicación de un cuestionario. Las respuestas se organizaron en categorías y demuestran que los estudiantes en formación consideran que la inclusión escolar es relevante, pero para que sea efectiva, es necesario invertir en una formación de calidad y la concentración del tema en unos pocos componentes curriculares no contribuye a la preparación de estos profesionales. En vista de esto, los estudiantes señalaron la necesidad de ofrecer más componentes y/o la transversalización del tema en el plan de estudios, además de oportunidades para relacionar la teoría y la práctica a través de pasantías en el área, lo que reduciría la sensación de falta de preparación y miedo, señalado por los estudiantes participantes de la investigación y también docentes que trabajan en escuelas de educación básica, como lo demuestran otros estudios sobre el tema. Es evidente la necesidad de repensar la formación de los docentes pedagógicos, preparándolos para actuar y consolidar la inclusión escolar.

Palabras clave: Formación docente. Graduandos en pedagogía. Inclusión escolar.

\section{Introdução}

Este artigo tem como tema a formação de professores em Pedagogia para atuar com estudantes Público-Alvo da Educação Especial (PAEE). Atualmente, vivemos o paradigma da Inclusão, no qual todas as pessoas 
independentemente de suas diferenças têm os mesmos direitos, inclusive à educação em escolas públicas ou privadas. A garantia desse direito mudou o cenário educacional brasileiro, no qual até a década de 1990 as pessoas com deficiência ficavam a margem da educação formal, frequentando instituições especializadas em cada deficiência. A perspectiva inclusiva reconfigurou a estrutura escolar; a Educação Especial que era ofertada às pessoas com deficiência paralelamente à educação básica passou a fazer parte do sistema educacional, estruturando-se como "modalidade de educação escolar oferecida preferencialmente na rede regular de ensino, para educandos com deficiência, transtornos globais do desenvolvimento e altas habilidades ou superdotação" (BRASIL, 1996).

Assim, a Educação Especial se organiza como suporte ao ensino escolar por meio do Atendimento Educacional Especializado (AEE) oferecido dentro da própria escola ou em instituições especializadas, as quais devem oferecer atendimento como suporte suplementar ou complementar, sem substituí-lo. E, nesse novo cenário, o pedagogo, professor que atua na educação infantil e nos anos iniciais do ensino fundamental, precisa de formação que atenda às especificidades do exercício de suas atividades docentes, como previsto nas atuais leis que regulamentam a educação, como a Lei de Diretrizes e Bases da Educação Nacional de 1996 e a Política Nacional de Educação Especial na perspectiva da Educação Inclusiva de 2008

Para organizar a formação de professores em nível superior, as Diretrizes Curriculares Nacionais para a Formação de Professores da Educação Básica em nível superior, curso de licenciatura, de graduação plena (2002), estabelecem que a organização dos cursos deve preparar esses profissionais para:

I - O ensino visando à aprendizagem do aluno;

II - O acolhimento e o trato da diversidade;

III - O exercício de atividades de enriquecimento cultural;

IV - O aprimoramento em práticas investigativas; 
$V$ - A elaboração e a execução de projetos de desenvolvimento dos conteúdos curriculares;

$\mathrm{VI}$ - O uso de tecnologias da informação e da comunicação e de metodologias, estratégias e materiais de apoio inovadores; VII - O desenvolvimento de hábitos de colaboração e de trabalho em equipe (BRASIL, 2002).

Os cursos de formação de professores em ensino superior devem preparar os futuros profissionais para atuar na diversidade e ensinar a todos os alunos independentemente das diferenças de cada um.

Além disso, segundo o referido documento, O Projeto Político Pedagógico dos cursos de formação de professores deve contemplar:

I - As competências referentes ao comprometimento com os valores inspiradores da sociedade democrática;

II - As competências referentes à compreensão do papel social da escola;

III - As competências referentes ao domínio dos conteúdos a serem socializados, aos seus significados em diferentes contextos e sua articulação interdisciplinar;

IV - As competências referentes ao domínio do conhecimento pedagógico;

$\checkmark$ - As competências referentes ao conhecimento de processos de investigação que possibilitem o aperfeiçoamento da prática pedagógica;

$\mathrm{VI}$ - As competências referentes ao gerenciamento do próprio desenvolvimento Profissional (BRASIL, 2002).

Preparar esses professores para atuar na perspectiva inclusiva, ensinando todos os alunos, é o requisito de uma sociedade democrática, acesso de todos ao conhecimento, na qual a escola forma cidadãos.

É importante pensarmos no papel da escola em nossa sociedade, de acordo com Gatti (2010) o papel da escola é ensinar e cabe aos professores, os responsáveis por essa prática em sala de aula, atuar de forma eficiente, daí a necessidade de formar profissionais que tenham condições de lidar com problemas complexos e variados, como o ensino e aprendizagem de estudantes diferentes, com habilidades, necessidades e dificuldades variadas. 
Logo, a formação inicial deve ser pensada a partir da função social da escola - de ensinar o conhecimento historicamente produzido a todos os alunos, pois esse é um direito de todos inclusive dos alunos com deficiência, com transtornos globais do desenvolvimento e com altas habilidades/superdotação, atualmente denominados estudantes PúblicoAlvo da Educação Especial (PAEE), ou seja, estudantes que, além de frequentar a escola pública ou privada, têm direito ao AEE no contraturno.

O tema formação de professores é constantemente discutido, foco de estudos e pesquisas, e, por isso, conforme Lüdke e Scott (2018), precisamos elaborar currículos que atendam as demandas dos processos de ensino e aprendizagem, e a inclusão de estudantes PAEE na educação básica é uma demanda atual.

Ao discorrer sobre o tema, Jesus e Effgen (2012, p.20) explicam a necessidade de entender como a escola está lidando com a inclusão escolar de estudantes PAEE e de entender a importância de refletir sobre essa realidade nos processos de formação docente, pois é preciso "investir maciçamente na formação inicial e continuada do educador".

Assim, considerando a legislação vigente, em especial aquelas que regulamentam a formação de professores, especificamente a do pedagogo, é possível depreender que, na formação inicial, todos os futuros professores da Educação Básica devem desenvolver competências para atuar também com estudantes PAEE em qualquer nível de ensino.

Com o objetivo de garantir essa formação, o Conselho Nacional de Educação (CNE) tem deliberado Resoluções para que os cursos de formação inicial ofereçam disciplinas e/ou conteúdos relacionados à inclusão escolar nos cursos de licenciatura, destacando-se as disciplinas de Libras e de Educação Especial, obrigatórias nos cursos de Pedagogia. Entretanto, como argumenta Pletsch (2009, p. 150):

Limitar-se a oferecer uma disciplina com conteúdos sobre crianças com necessidades especiais, sem maior reflexão e aprofundamento acerca das capacidades e individualidades 
humanas, pode acabar auxiliando a manutenção de práticas segregacionistas.

Além de contribuir para o sentimento de despreparo dos professores ao atuarem na educação básica.

A discussão sobre formação de professores consiste em um tema constantemente em destaque no cenário educacional e precisa considerar diversos aspectos, como a diversidade regional e socioeconômica de nosso país, o despreparo de professores formadores na formação de professores que saibam atuar na diversidade, a estruturação de currículos que contemplem conhecimentos que embasem a prática docente na escola inclusiva, como destacam Bueno (2001), Gatti (2010), Glat e Pletsch (2004), Saviani (2009), dentre outras referências na área.

Considerando a relevância do tema formação de professores para atuar na perspectiva inclusiva e a consequente importância do currículo de formação dos cursos de licenciatura nesse processo formativo, este artigo tem como objetivo discutir a formação de professores no curso de pedagogia para atuar com estudantes PAEE.

Para tanto, em termos metodológicos, optou-se pela pesquisa descritiva, numa abordagem qualitativa. Essa escolha se justifica por se tratar da apresentação de dados oriundos de uma realidade específica de formação de professores dentro do cenário nacional, ou seja, graduandos do curso de licenciatura em Pedagogia da Universidade Federal da Bahia (UFBA). A coleta de dados da pesquisa se deu por meio de dois instrumentos, o levantamento bibliográfico e o questionário, aplicado com os estudantes do referido curso.

O artigo está organizado em sete seções, sendo a primeira esta breve introdução da pesquisa realizada, seguida por duas seções de fundamentação teórica que discutem, respectivamente, a perpectiva inclusiva em sua interface com a formação de professores e o currículo de licenciatura em Pedagogia da UFBA. Posteriormente, são apresentados os 
aspectos metodológicos e os resultados e discussões em torno dos dados coletados, concluindo com a seção de considerações finais e referências.

\title{
A perspectiva inclusiva na formação de professores
}

O processo de inclusão de estudantes com deficiência, transtorno do espectro autista e altas habilidades/superdotação nos diversos níveis do ensino depende de uma gama de condições que, quando asseguradas, promovem o desenvolvimento do potencial de cada estudante, mas, por outro lado, quando não garantidas, comprometem a aprendizagem e dificultam a afetiva participação desses alunos no contexto escolar. Dentre essas condições, é possível citar a acessibilidade atitudinal, arquitetônica ao conhecimento, entre outras. A formação docente adquire um papel central nesse processo de inclusão.

Não raro, ouve-se dizer que os professores concluem os cursos de licenciatura sentindo-se despreparados para acolher as demandas específicas de seus alunos. Essa sensação de despreparo parece alcançar proporção ainda maior quando eles se encontram diante do desafio de ensinar um estudante público-alvo da Educação Especial.

\begin{abstract}
Atualmente a relevância dos estudos que buscam conhecer e analisar a formação inicial de professores na perspectiva da Educação Inclusiva pauta-se em compromisso assumido pela sociedade brasileira ao preconizar a educação como um direito de todos e a importância de se garantir acesso e permanência do público alvo da Educação Especial, preferencialmente no ensino comum (MONICO; MORGADO; ORLANDO, 2018, p.42).
\end{abstract}

Poker, Valentim e Garla (2017, p. 880) fazem um levantamento e apontam os resultados de estudos anteriores que buscaram investigar essa temática:

Em pesquisas sobre a avaliação da formação recebida para atuar com a inclusão de alunos público alvo da Educação Especial, Barbosa-Vioto e Vitaliano (2013) encontraram que $55,9 \%$ dos participantes sinalizam que o curso de Pedagogia 
contribuiu parcialmente para atuar na inclusão desses alunos. Já, 28,8\% dos participantes avaliaram que a preparação oferecida no curso era insuficiente.

A presença desse estudante, em sala, lança luz sobre aspectos que deveriam ser objeto de reflexão cotidiana do educador - sua concepção de aprendizagem e de prática de ensino. Rever a dinâmica em sala de aula, adaptar materiais pedagógicos, repensar a proposta avaliativa são ações desafiadoras num contexto que tem dificuldade de reconhecer a heterogeneidade dos estudantes e de suas formas de aprender.

A formação inicial em Pedagogia tem como objetivo oferecer, ao professor, a oportunidade de compreender o significado da escola inclusiva e o seu papel nesse processo com base em uma concepção inovadora de escola, ensino, aprendizagem, currículo e mesmo de aluno. Todos os outros conhecimentos advindos de situações inusitadas e específicas propostas pela inclusão educacional serão enfrentados no cotidiano escolar de forma criativa, coletiva e crítica, com a participação de todos os agentes envolvidos. Em uma parceria colaborativa, profissionais do Atendimento Educacional Especializado, professores da sala regular, gestores, funcionários e pais podem planejar e criar estratégias inovadoras em direção à melhoria das condições de ensino de todos os alunos (POKER; VALENTIM; GARLA, 2017, p. 887-888).

Contudo, nem sempre a inovação faz parte da realidade vivenciada nas escolas. Ainda se preserva uma lógica homogeneizante e meritocrática que vê na diversidade uma ameaça ao fazer pedagógico.

A centralidade das necessidades educacionais nas características individuais retirou da pessoa considerada deficiente suas necessidades de aluno. A própria formação de professores priorizou, por muitos anos, as técnicas e os recursos específicos em detrimento de análises do sistema educacional, em seus aspectos econômicos, sociais e políticos. [...] O fato de a proposta de formação de professores para a Educação Especial se organizar pela deficiência (biológica ou psicológica) dos alunos secundariza $\bigcirc$ fazer pedagógico (MICHELS, 2017, p.36). 
Segundo Castanho e Freitas (2006, p.1), "[...] a universidade é um lugar onde os valores e práticas de educação inclusiva precisam ser vivenciadas", logo o conhecimento teórico atrelado à experiência prática na área de Educação Especial deveria constituir o alicerce primário para a construção de uma escola mais plural, diversa e alinhada aos princípios inclusivos.

A Resolução CNE/CP n 1/2002 estabelece as Diretrizes Curriculares Nacionais para a Formação de Professores da Educação Básica, em nível superior, curso de licenciatura, de graduação plena, definindo em seus objetivos e metas que "as instituições de ensino superior devem prever, em sua organização curricular, formação docente voltada para a atenção à diversidade e que privilegie conhecimentos sobre as especificidades dos alunos com necessidades educacionais especiais" (BRASIL, 2002).

A referida Resolução enumera o conjunto de competências as quais a formação de professores deve garantir e destaca que o processo formativo deve ofertar conhecimentos a respeito dos ditos alunos com necessidades educacionais especiais, conforme é possivel comprovar no trecho a seguir, extraído do Art. 60, Inciso VI (idem):

$\S 2^{\circ}$ As referidas competências deverão ser contextualizadas e complementadas pelas competências específicas próprias de cada etapa e modalidade da educação básica e de cada área do conhecimento a ser contemplada na formação. $\S 3^{\circ}$ A definição dos conhecimentos exigidos para a constituição de competências deverá, além da formação específica relacionada às diferentes etapas da educação básica, propiciar a inserção no debate contemporâneo mais amplo, envolvendo questões culturais, sociais, econômicas e o conhecimento sobre o desenvolvimento humano e a própria docência, contemplando: I - cultura geral e profissional; II conhecimentos sobre crianças, adolescentes, jovens e adultos, aí incluídas as especificidades dos alunos com necessidades educacionais especiais e as das comunidades indígenas; III conhecimento sobre dimensão cultural, social, política e econômica da educação; IV - conteúdos das áreas de conhecimento que serão objeto de ensino; $V$ - conhecimento pedagógico; VI - conhecimento advindo da experiência.

Sendo a Educação Especial uma modalidade transversal de ensino, conclui-se que os cursos de formação de professores deveriam garantir que 
os cursistas tivessem contato com os conhecimentos produzidos na área, bem como sua formação deveria contemplar experiências práticas e devidamente supervisionadas, com os estudantes público-alvo da Educação Especial. Diante disso, a presente investigação buscou analisar a proposta curricular do curso de Pedagogia da Universidade Federal da Bahia, no que tange à formação de professores e a perspectiva inclusiva.

\section{Currículo de Pedagogia na UFBA}

Analisando os Projetos Pedagógicos do Curso de Pedagogia (diurno e noturno) da UFBA, foi possível perceber que os componentes curriculares disponibilizados para ambos os turnos são os mesmos, a variação está nos semestres em que os componentes obrigatórios são ofertados.

Existe um componente de natureza obrigatória, intitulado na matriz curricular vigente como Educação Especial na Perspectiva Inclusiva, ofertado com carga horária de 68 horas semanais, distribuídas em 34h teóricas, 17h práticas e 17h de prática pedagógica como componente curricular. No curso diurno, ele aparece disponibilizado no $4^{\circ}$ semestre, ao passo que no curso noturno, este componente é ofertado a partir do $3^{\circ}$ semestre.

O outro componente relacionado à área de Educação Especial que também apresenta caráter obrigatório e carga horária de 68h é denominado LIBRAS e é ofertado pelo Instituto de Letras da UFBA.

Os componentes curriculares optativos relacionados à Educação Especial ofertados no curso de Pedagogia são Educação do Deficiente Mental, Educação de Surdos e Cognição e Aprendizagem nas Deficiências Sensoriais. Os componentes obrigatórios são ofertados todos os semestres, ao passo que os optativos são ofertados de acordo com a demanda do curso em relação aos componentes obrigatórios e, consequentemente, com a disponibilidade de carga horária dos docentes para ofertá-los.

Deimling e Caiado (2012) realizaram uma pesquisa sobre formação de professores em três universidades paulistas. O estudo demonstrou que 
nenhum dos cursos analisados oferecia estágios específicos em Educação Especial. Essa realidade assemelha-se a do curso analisado nesta pesquisa, pois as experiências de estágio delineadas no currículo não contemplam a área de Educação Especial.

A partir de uma pesquisa que investigou as matrizes curriculares de cursos de licenciatura, Pedroso, Campos e Duarte (2013, p. 46) concluíram que:

A organização curricular dos cursos de licenciatura não tem garantido os saberes pedagógicos necessários para responder às demandas da escola básica pública, principalmente em relação ao processo de ensino-aprendizagem de alunos com necessidades educacionais especiais.

Sabe-se que dificilmente um curso de graduação conseguirá garantir os conhecimentos necessários para atender às especificidades de todos os estudantes, tendo em vista a diversidade humana e dos contextos educacionais. Muito menos se quer afirmar que a questão da inclusão se esgotaria na dimensão da formação docente. "Entendemos nesse sentido que uma formação adequada de professores precisa reconsiderar e ressignificar em suas políticas públicas as realidades dos sistemas de ensino, o tipo de alunado, a organização, o funcionamento e a gestão das escolas" (RIBEIRO, 2012, p.77). É preciso, portanto, atentar para as condições físicas e organizacionais das escolas, para a frágil ou ausente articulação entre o ensino comum e o atendimento educacional especializado, enfim cabe levar em consideração as demais questões nas quais configuram adversidades ao êxito do processo inclusivo.

Monico, Morgado e Orlando (2018) realizaram um levantamento das dissertações de mestrado e teses de doutorado publicadas no Portal de Teses e Dissertações da Coordenação de Aperfeiçoamento Pessoal de Nível Superior (CAPES) e a Biblioteca Nacional de Teses e Dissertações (BDTD), no período de 2008 a 2015, que abordaram a formação inicial do professor na perspectiva da Educação Inclusiva e constataram que apenas uma tese e três dissertações foram encontradas. 
Essa escassez de trabalhos acadêmicos sobre o tema levou as autoras a refletirem que:

Embora em 2008, início do período estudado, termos como marco a Política Nacional de Educação Especial na Perspectiva da Educação Inclusiva (Brasil, 2008), a aprovação e publicação do Decreto n 6949 (2009) e ainda, o registro de avanço nas matrículas de pessoas com deficiência no ensino comum, tais dados parece que pouco impulsionaram os estudos acadêmicos voltados para a formação inicial na perspectiva da Educação Inclusiva (MONICO, MORGADO e ORLANDO, 2018, 44).

Somada à escassez de pesquisas na área, outro fator merecedor de destaque é a concentração das publicações nas regiões sudeste e sul, no intervalo de tempo da coleta de dados e, por conseguinte, a inexistência de teses e dissertações publicadas nas regiões norte e nordeste do país.

Ainda há muito que discutir e caminhar no sentido de construir uma prática docente inclusiva alicerçada na formação inicial do professor, visto que a estrutura curricular dos cursos de formação de professores não garante solidez de conhecimento, em virtude de ofertar poucos componentes curriculares que abordam a temática da Educação Especial. O contato incipiente e superficial não permite atender adequadamente às especificidades dos estudantes público-alvo da Educação Especial, muito menos construir uma visão crítica e reflexiva sobre o processo inclusivo.

Os resultados apontam que é quase inexistente o número de disciplinas que tratam da temática educação especial e/ou inclusão escolar nas licenciaturas pesquisadas. Sua invisibilidade só não é completa por conta da presença, na sua maioria, da disciplina Língua Brasileira de Sinais (LIBRAS), conforme indicado, regulamentada pelo Decreto 5626 (2005, p.1), determinou que "a Libras deve ser inserida como disciplina curricular obrigatória nos cursos de formação de professores para o exercício do magistério, em nível médio e superior, e nos cursos de Fonoaudiologia". Parece que há um impasse que precisa ser pesquisado, primeiro os alunos adentram as escolas, garante-se o acesso, depois pensa-se em sua permanência e apropriação dos conteúdos escolares. Relega-se, talvez, à formação continuada o preparo deste professor para atuar junto aos alunos público alvo da 
Educação Especial (MONICO, MORGADO e ORLANDO, 2018, p. 46).

A formação continuada tem se configurado como o momento no qual o professor vai buscar conhecimento teórico-prático para responder às necessidades específicas dos alunos, conhecimento este que the faltou em sua formação inicial. No entanto, a formação inicial precisa ser concebida como uma base sólida para a aprendizagem contínua do professor, permitindo reelaborar os saberes iniciais a partir das experiências cotidianamente vivenciadas no contexto escolar.

A inclusão tem sido tratada como inserção ou disponibilização de oportunidades para que esse público tenha acesso ao ensino comum regular. As conquistas legais na área da Educação Especial constituem um recurso imprescindível para garantir 0 acesso dos estudantes com deficiência, TEA e AH/SD no contexto da escola comum. No entanto, a permanência com qualidade ainda precisa ser alvo de uma discussão mais aprofundada e problematizadora nos níveis da formação inicial e continuada de professores.

\section{Método}

O artigo consiste em um estudo descritivo de abordagem qualitativa. O estudo descritivo tem como objetivo conhecer e interpretar uma realidade, sem a pretensão de interferir diretamente ou modificar tal cenário (MARCONI; LAKATOS, 2019; GIL, 2019). Este tipo de pesquisa expõe as características de determinado grupo ou fenômeno, visando descrevê-los, classificá-los ou interpretá-los. "Quando o estudo é de caráter descritivo e o que se busca é o entendimento do fenômeno como um todo, na sua complexidade, é possível que uma análise qualitativa seja a mais indicada" (GODOY, 1995, p. 63).

Sendo assim, a presente pesquisa versou sobre a formação de professores no curso de pedagogia da Universidade Federal da Bahia, essencialmente no que concerne à área de Educação Especial. Os achados 
resultaram da articulação dos dados coletados através do levantamento bibliográfico sobre a temática, por intermédio das respostas obtidas do questionário aplicado a graduandos do curso de Pedagogia e por meio da análise da proposta curricular em vigor no referido curso.

A presente pesquisa foi realizada considerando todos os aspectos éticos para realização de pesquisas em Seres Humanos, solicitando, aos participantes, anuência de participação por meio de termo de Consentimento Livre e Esclarecido com esclarecimentos sobre riscos e benefícios da participação na pesquisa.

Foram analisados os projetos pedagógicos dos cursos de Pedagogia, ofertados nos turnos diurno e noturno pela Universidade Federal da Bahia, especificamente no que tange aos componentes curriculares vinculados à área de Educação Especial.

O questionário possuía oito questões abertas sobre a qualidade da formação inicial de professores para atuar com estudantes público-alvo da Educação Especial e as respostas obtidas foram organizadas em categorias de análise. Participaram da pesquisa 22 estudantes e os questionários foram aplicados através do contato direto com os participantes do estudo.

Vale ressaltar que nos resultados apresentados na próxima seção será possível perceber que, em termos quantitativos, o número de respostas ultrapassa, em algumas questões, o número total de participantes, porque, em uma mesma pergunta do questionário, alguns participantes apontaram mais de um aspecto.

\section{Resultados}

Dos 22 estudantes do curso de Pedagogia que responderam aos questionários, dois são do sexo masculino e 20 do sexo feminino, com idades variadas, como apresentam os dados do quadro 1:

QUADRO 1 - Faixa etária dos participantes

\begin{tabular}{|c|c|}
\hline Faixa Etária & $\mathbf{N}^{\circ}$ de participantes \\
\hline $20-25$ anos & 12 \\
\hline $26-35$ anos & 4 \\
\hline
\end{tabular}




\begin{tabular}{|c|c|}
\hline $36-45$ anos & 3 \\
\hline Acima de 45 anos & 2 \\
\hline Idade não informada & 1 \\
\hline
\end{tabular}

Fonte: Autores (2019).

A maioria dos participantes tem entre 20 e 25 anos e estão em diferentes momentos do curso, conforme dados organizados no quadro 2.

QUADRO 2 - Número de participantes por período do curso

\begin{tabular}{|c|c|}
\hline Semestre & $\mathbf{N}^{\circ}$ de Participantes \\
\hline Segundo & 1 \\
\hline Terceiro & 1 \\
\hline Quarto & 7 \\
\hline Quinto & 3 \\
\hline Sexto & 3 \\
\hline Sétimo & 3 \\
\hline Oitavo & 2 \\
\hline Situação não regular & 2 \\
\hline
\end{tabular}

Fonte: Autores (2019).

Conforme a grade curricular vigente do curso de Pedagogia 0 componente curricular Educação de Pessoas com Necessidades Educativas Especiais deve ser ofertado no quarto semestre, no entanto os dados obtidos mostram que os estudantes nem sempre seguem a sequência indicada na grade e cursam o componente em diferentes momentos.

Ao serem questionados sobre a opinião que têm a respeito do processo de inclusão escolar do público alvo da educação especial há uma variedade de respostas, conforme apontado no quadro 3:

QUADRO 3 - Opinião sobre inclusão escolar

\begin{tabular}{|c|c|}
\hline Categorização de respostas & $\begin{array}{c}\mathbf{N}^{\circ} \text { de } \\
\text { respostas }\end{array}$ \\
\hline A inclusão é relevante & 7 \\
\hline É preciso profissionais e materiais adequados & 6 \\
\hline Dificuldades de Operacionalizar a perspectiva inclusiva na prática & 6 \\
\hline $\begin{array}{c}\text { A inclusão propicia a participação efetiva de pessoas excluídas da } \\
\text { sociedade }\end{array}$ & 4 \\
\hline $\begin{array}{c}\text { A inclusão requer ação e comprometimento respeitando as } \\
\text { necessidades específicas de cada um }\end{array}$ & 3 \\
\hline
\end{tabular}




\begin{tabular}{|c|c|}
\hline É preciso acreditar na inclusão e ir além das políticas públicas & 3 \\
\hline A inclusão precisa ser mais trabalhada na formação de professores & 2 \\
\hline Inclusão é direito e dever do Estado & 2 \\
\hline Não conhecem o termo PAEE & 2 \\
\hline A inclusão deve mudar a percepção dos profissionais & 1 \\
\hline Todos os lugares devem ser adaptados & 1 \\
\hline Não respondeu & 1 \\
\hline
\end{tabular}

Fonte: Autores (2019).

A maioria dos estudantes participantes reconhece a relevância da inclusão escolar, mas pontuam aspectos que precisam de atenção, como a falta de professores qualificados, a escassez de recursos e materiais adaptados, as dificuldades de efetivar a inclusão em sala de aula e a necessidade de investimento em formação docente. Temas que coincidem com pesquisas e estudos da área de educação especial, como pontuado por Gatti (2010) e Saviani (2009) e que também estão representadas nas seguintes respostas dos estudantes participantes:

Acho imprescindível, mas necessário que [o processo de inclusão] seja feito por profissionais comprometidos, dispostos e especializados. É importante e fundamental para o desenvolvimento do sujeito e um privilégio para aqueles que podem conviver e ver na prática as possibilidades reais de evolução do ser humano apesar de todas as barreiras (E 1).

Que é possível a inclusão desses estudantes, mas que é imprescindível a ação e o comprometimento dos diversos atores sociais para que ela aconteça de fato. Não basta a legislação, se faz necessária a conjugação de esforços por parte da família, da escola, dos profissionais da educação regular e da educação especial, do governo para efetivar políticas públicas para esse fim (E 3).

É interessante pontuar que, mesmo cursando o componente curricular que desenvolve o tema, dois estudantes afirmaram desconhecer o termo PAEE, o qual demonstra que o uso de outros termos, anteriores a Política Nacional de Educação Especial na Perspectiva da Educação Inclusiva de 2008, ainda estão presentes no cotidiano da população, demonstrando a necessidade de divulgar mais a legislação e os termos vigentes, para as 
pessoas conhecerem as políticas que respaldam a educação e quem está contemplado nela.

As respostas à segunda questão sobre o que o currículo do curso de Pedagogia contempla na área de Educação Especial e Inclusiva estão organizadas no Quadro 4.

QUADRO 4 - Componentes Curriculares Cursados

\begin{tabular}{|c|c|}
\hline Componentes Curriculares & $\mathbf{N}^{\circ}$ de respostas \\
\hline Componentes Obrigatórios e Optativos & 20 \\
\hline Número insuficiente de componentes curriculares & 9 \\
\hline Formação Docente para atuar com alunos PAEE & 2 \\
\hline Aspectos Históricos e Legais & 1 \\
\hline PAEE & 1 \\
\hline Não respondeu & 1 \\
\hline
\end{tabular}

Fonte: Autores (2019).

O componente obrigatório citado intitula-se Educação de Pessoas com Necessidades Educativas Especiais e tem por objetivo:

Analisar criticamente a construção histórico-social do processo de exclusão/inclusão das pessoas com necessidades educativas especiais nos âmbitos político-econômico, social e educacional, destacando as ações, recursos e estratégias pedagógicas para favorecer o processo de inclusão escolar de acordo com o nível de ensino (EXTRAÍDO DA EMENTA DO COMPONENTE).

E os componentes optativos são as disciplinas Libras, Educação de Surdos e Educação do Deficiente Mental. Se considerarmos o total de disciplinas que compõem o currículo do curso e a atual relevância do tema inclusão escolar, depreendemos que há poucos componentes curriculares, como os próprios estudantes pontuam na segunda categoria, e fica explícito na resposta do estudante E15 "apenas um componente não é suficiente para dar conta de toda complexidade que esta área demanda".

Os resultados apontaram a necessidade de repensar a estrutura curricular do curso de forma a garantir mais espaços de discussão sobre as temáticas em torno da inclusão escolar. Uma ação que poderia alcançar 
parcialmente esse objetivo seria a de transversalizar o debate sobre inclusão escolar nos diversos componentes curriculares.

A terceira questão discorre sobre a formação em Educação Especial ofertada pelo curso de Pedagogia. A partir da análise das respostas, evidenciou-se a predominância da insatisfação dos estudantes, como demonstrado no quadro 5.

QUADRO 5 - Avaliação da formação na área de Educação Especial

\begin{tabular}{|c|c|}
\hline Categoria & $\mathbf{N}^{\circ}$ de respostas \\
\hline Formação Satisfatória & 6 \\
\hline Formação Insatisfatória & 13 \\
\hline Insuficiente & 3 \\
\hline
\end{tabular}

Fonte: Autores (2019).

Além de opinar sobre a formação ser satisfatória ou não, foi solicitado que eles justificassem a resposta. Dentre os relatos obtidos, destacamos:

Acho que meu curso (pedagogia) deveria ter mais disciplinas que fossem da Educação Especial, porque o professor muitas vezes vai ser o primeiro a identificar alguma necessidade no aluno, por isso ele deve estar preparado para isso (E21).

Gostaria que houvesse mais oportunidades no currículo para aprofundar os conhecimentos nesta área, o que seria de grande importância para que o pedagogo esteja melhor preparado para promover a inclusão em sala de aula (E17).

A insatisfação com a formação ofertada é evidente e está relacionada à questão seguinte, cujos resultados foram organizados no quadro 6.

QUADRO 6 - Lacunas apontadas na formação docente

\begin{tabular}{|c|c|}
\hline Categoria & Número \\
\hline Atividades teórico práticas & 18 \\
\hline Não respondeu & 3 \\
\hline Formação continuada & 2 \\
\hline Interdisciplinaridade do tema & 1 \\
\hline Profissionais especializados & 1 \\
\hline Maior carga horária & 1 \\
\hline
\end{tabular}




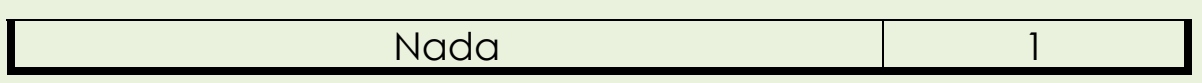

Fonte: Autores (2019).

As respostas obtidas demonstram que os estudantes estão em sua maioria insatisfeitos com a formação ofertada por não conseguirem relacionar o conteúdo aprendido no decorrer do curso (nas disciplinas teóricas) com a prática. E isto se deve em parte a própria estrutura curricular, na qual a abordagem de temas relativos à Educação Especial não acontecer de forma interdisciplinar em outros componentes. Outra razão que parece justificar essa queixa de falta de articulação teórica prática é a inexistência de estágio curricular na área de Educação Especial, que também é pontuada por um dos participantes: "Uma experiência real nessa área, acredito que deveria ter um estágio de Educação Especial" (E12).

Ao serem questionados sobre o que falta para a escola atender adequadamente estudantes PAEE, as respostas foram contabilizadas no quadro 7:

QUADRO 7 - Aspectos necessários à efetivação da inclusão escolar

\begin{tabular}{|c|c|}
\hline Categoria & N $^{\circ}$ de respostas \\
\hline Conhecer especificidades do aluno PAEE & 17 \\
\hline Mudança de perspectiva sobre inclusão escolar & 16 \\
\hline Parceria entre professores da sala regular e especializado & 1 \\
\hline Respeito às diferenças & 1 \\
\hline Não vê ponto de mudança & 1 \\
\hline Não respondeu & 1 \\
\hline
\end{tabular}

Fonte: Autores (2019).

As categorias obtidas podem ser exemplificadas nas seguintes respostas:

De disciplinas que contemplem a educação especial nos diversos níveis e modalidades de ensino: na educação infantil, no ensino fundamental, no ensino médio, na EJA e no ensino superior (E22). 
Uma experiência real nessa área acredito que deveria ter um estágio de Educação Especial (E8).

A fim de tentar superar o discurso do despreparo da escola e dos professores, é preciso que a produção de conhecimento sobre Educação Inclusiva ocorra de modo transversal no currículo da Pedagogia e demais licenciaturas, sendo esta discussão contemplada nos diversos componentes curriculares, a exemplo da Educação Infantil, Alfabetização e Letramento, EJA, Currículo, Didática, Gestão Educacional, Políticas em Educação, etc. Mas como fazer isso dentro de uma estrutura fragmentada e segmentada de currículo, que não alcança a interdisciplinaridade na produção do conhecimento?
A interdisciplinaridade exige uma reflexão profunda e inovadora sobre o conhecimento, que demonstra a insatisfação com o saber fragmentado, com base na reflexão crítica sobre a própria estrutura do conhecimento, na intenção de superar a distância entre as disciplinas e no desejo de renovar o próprio papel dos professores na formação dos estudantes para o mundo (SILVA; CUSATI; GUERRA, 2018, p. 987-988).

Ao questionarmos qual sentimento os estudantes do curso de Pedagogia têm ao saberem que um aluno PAEE está na turma em que eles serão professores, é possível perceber o sentimento de despreparo, pontuado também por professores em serviço, pois como argumenta Pletsch $(2009, \mathrm{~s} / \mathrm{p})$ "muitas vezes a falta de preparo e informação impede o professor de desenvolver uma prática pedagógica sensível às necessidades do aluno especial incluído".

Outros sentimentos que emergiram quando questionados sobre a possibilidade de receber um estudante PAEE em sua turma foram elencados pelos participantes, os quais aparecem listados no quadro a seguir:

QUADRO 8 - Sentimentos
Sentimento
$\mathrm{N}^{\circ}$ de respostas 


\begin{tabular}{|c|l|}
\hline Preocupação/Medo & 6 \\
\hline Aflição/ Desespero & 1 \\
\hline Alívio & 1 \\
\hline Acolhimento & 1 \\
\hline Curiosidade & 1 \\
\hline Alegria & 1 \\
\hline Compaixão & 1 \\
\hline Impotência & 1 \\
\hline Não respondeu & 1 \\
\hline
\end{tabular}

Fonte: Autores (2019).

Os sentimentos elencados evidenciam a sensação de incapacidade e medo frente ao novo, ao desconhecido, o que requer formação que atenda tal demanda, pois:

O atual e grande desafio posto para os cursos de formação de professores é o de produzir conhecimentos que possam desencadear novas atitudes que permitam a compreensão de situações complexas de ensino, para que os professores possam desempenhar de maneira responsável e satisfatória seu papel de ensinar e aprender para a diversidade (PLETSCH, $2009 \mathrm{~s} / \mathrm{p})$.

Tal sentimento fica evidente também na fala de E5: "Preocupação seria o primeiro sentimento, mas posteriormente com certeza amadurecimento e melhoria nas práticas pedagógicas".

Esses achados foram compatíveis com outros estudos realizados, tais como o de Costa (2007) que, em sua tese a respeito dos sentimentos dos professores frente ao processo de inclusão escolar, concluiu que, embora os professores por ela entrevistados,

Apresentassem aspectos negativos, ou seja, respostas em que apontaram dificuldades, como frustração, despreparo e insegurança frente à inclusão (o que certamente dificulta $\circ$ bom desempenho profissional e, consequentemente, 0 sucesso do referido processo), revelaram buscar melhores soluções e caminhos para se adaptarem ao aluno com deficiência, o que contempla um dos princípios de inclusão escolar, a de que uma criança com deficiência, incluída em classe comum do ensino regular, deve receber um atendimento diferenciado de acordo com suas necessidades (p.82). 
E, quando questionados sobre a possibilidade de ensinar um estudante público-alvo, os participantes em sua maioria reafirmam o despreparo, como demonstrado no quadro 9.

QUADRO 9 - Condições para ensinar estudantes PAEE

\begin{tabular}{|c|c|}
\hline Categoria & $\mathbf{N}^{\circ}$ de respostas \\
\hline Sim com suporte & 5 \\
\hline Não & 13 \\
\hline Não respondeu & 2 \\
\hline Sim & 1 \\
\hline
\end{tabular}

Fonte: Autores (2019).

Os resultados evidenciaram que $59 \%$ dos participantes consideraram não ter conhecimento suficiente para incluir alunos PAEE e 22,7\% conseguiriam ensinar esses estudantes desde que tivessem suporte.

A partir dos dados coletados, foi possível constatar que a formação inicial não tem ofertado suporte teórico, metodológico e prático suficiente que permita avaliar a qualidade da inovação educativa que deve ser introduzida constantemente nas escolas com o intuito de responder aos desafios que emergem no cotidiano escolar, nem tão pouco tem possibilitado momentos de reflexão, proporcionando uma visão crítica e realista da prática docente.

Sendo assim,

No que concerne à formação de professores, é necessária uma verdadeira revolução nas estruturas institucionais formativas e nos currículos da formação. As emendas já são muitas. A fragmentação formativa é clara. É preciso integrar essa formação em currículos articulados e voltados a esse objetivo precípuo (GATTI, 2010, p.1375).

A necessidade de formação de qualidade é uma exigência que pode impactar positivamente no sucesso escolar de estudantes PAEE e, 
consequentemente, na garantia de direitos para a efetivação de uma sociedade democrática, daí a relevância do tema.

\section{Considerações finais}

O debate sobre a qualidade da formação de professores parece ganhar ainda maior complexidade quando se trata da atuação docente na perspectiva inclusiva. O estudo realizado demonstrou que a formação inicial, avaliada por meio dos relatos dos graduandos do curso de Pedagogia, mostrou-se insuficiente em termos teórico-prático. Os achados apontaram a existência de poucos componentes curriculares relacionados à Educação Especial na matriz curricular do curso, sendo apenas um de caráter obrigatório e três de caráter optativo.

Verificou-se também a ausência de estágio específico na área, fato que os participantes consideraram fragilizar a sua formação em termos de experiência prática. Esse aspecto muito possivelmente contribui para o sentimento de despreparo diante do desafio de incluir os estudantes PAEE na escola comum, relatados por muitos participantes.

Apesar do sentimento de despreparo, a maioria dos participantes reconhece a importância da inclusão escolar, opinião que apresenta consonância com o reconhecimento de que educação é direito de todos independente de sua condição física, sensorial, psíquica etc.

Os participantes apontaram também a falta de recursos e de materiais adaptados como uma barreira para a efetiva inclusão. Somado a isso, outro aspecto ressaltado foi carência de professores qualificados para efetivar 0 processo inclusivo e para dar suporte à inclusão. A insuficiência de professores qualificados em sala de aula e de professores especialistas apareceu como principais fatores que comprometem a participação efetiva dos alunos em sala.

Torna-se, portanto, necessário refletir sobre a formação inicial e continuada de professores na perspectiva inclusiva, de modo a possibilitar maior suporte teórico, metodológico e prático, favorecendo que a 
produção de conhecimento sobre Educação Inclusiva transcenda o escopo dos componentes curriculares relativos à área de Educação Especial, visto que figuram insuficientes e passe a ocorrer de modo transversal no currículo da Pedagogia e demais licenciaturas.

\section{Referências}

BRASIL. Lei $\mathbf{n}^{\circ} \mathbf{9 . 3 9 4}$, de 20 de dezembro de 1996. Estabelece as diretrizes e bases da Educação nacional. Disponível em:

http://portal.mec.gov.br/seed/arquivos/pdf/tvescola/leis/. Acesso em: 20 jan. 2012.

BRASIL. Resolução CNE $n^{\circ} 1$ de 2002. Institui as Diretrizes Curriculares Nacionais para a Formação de Professores da Educação Básica, em nível superior, curso de licenciatura, de graduação plena. Disponível em:

http://portal.mec.gov.br/cne/arquivos/pdf/rcp01_02.pdf. Acesso em: 20 jan. 2012.

BUENO, J.G. A inclusão de alunos diferentes nas classes comuns do ensino regular. In: Temas sobre Desenvolvimento. São Paulo, v. 9, n. 54, p. 21-27, 2001.

CASTANHO, D. M.; FREITAS, S. N. Inclusão e prática docente no ensino superior. Revista Educação Especial, n. 27, p. 93-99, 2006. Disponível em: http://www.ufsm.br/revistaeducacaoespecial. Acesso em: 20 jan. 2012.

COSTA, M.C.S. Sentimentos de professores frente às dificuldades na prática da educação inclusiva de alunos com deficiência no ensino fundamental. 2007. 121f. Dissertação (Mestrado em Psicologia da Educação). Programa de Pós-graduação em Psicologia da educação: PUC, São Paulo, 2007.

DEIMLING, N. N. M.; CAIADO, K. R. M. Formação de professores para a educação inclusiva nos cursos de pedagogia das universidades públicas paulistas. Revista Teoria e Prática da Educação, v. 15, n. 3, p. 51-64, set./dez. 2012.

DOURADO, L. F. Políticas e gestão da educação no Brasil: múltiplas regulações e controle. Revista Brasileira de Política e Administração da Educação, v. 27, n. 1, p. 53-65, 2011.

GATTI, B. A. Formação de professores no Brasil: características e problemas. Educação e Sociedade, vol. 31, núm. 113, 2010.

GIL, A.C. Métodos e Técnicas de Pesquisa Social. $7^{a}$ edição, São Paulo: Atlas, 2019. 
GLAT, R.; PLETSCH, M. D. O papel da Universidade frente às políticas públicas para educação inclusiva. Revista Benjamin Constant, Rio de Janeiro, p. 3-8, 2004.

GODOY, A. Introdução à Pesquisa Qualitativa e suas possibilidades. São Paulo: Revista de Administração de Empresas, v.35, n.2, Mar./Abr. 1995.

GUERRA, M. das G. G. V.; CUSATI, I. C.; SILVA, A. X. da. Interdisciplinaridade e transdisciplinaridade: dos conhecimentos e suas histórias. Revista IberoAmericana de Estudos em Educação, Araraquara, v. 13, n. 03, p. 979-996, jul./set., 2018.

JESUS, D. M.; EFFGEN, A. P. S. Formação docente e práticas pedagógicas conexões, possibilidades e tensões. In: MIRANDA, T.G.; GALVÃO FILHO, T.A. O professor e a educação inclusiva: formação, práticas e lugares. EDUFBA, 2012.

LÜDKE, M.; SCOTT, D. O lugar do estágio na formação de professores em duas perspectivas: Brasil e Inglaterra. Educ. Soc., Campinas, v. 39, n. 142, p.109125, jan.-mar., 2018.

MARCONI, M. A.; LAKATOS, E.M. Fundamentos de Metodologia Científica. Grupo Editorial Nacional, 2019.

MICHELS, M. H. (org.). A formação de professores de Educação Especial no Brasil: propostas em questão. Florianópolis: UFSC/CED/NUP, 2017.

MONICO, P. A.; MORGADO, L. A. S.; ORLANDO, R. M. Formação inicial de professores na perspectiva inclusiva: levantamento de produções. Psicologia Escolar e Educacional, SP. Número Especial, 2018: 41-48.

MOREIRA, A. F. B.; KRAMER, S. Contemporaneidade, educação e tecnologia. Educação e Sociedade, v. 28, n. 100, p. 1037-1057, 2007.

PEDROSO, C. C. A.; CAMPOS, J. A. P. P.; DUARTE, M. Formação de professores e educação inclusiva: análise das matrizes curriculares dos cursos de licenciatura. Educação Unisinos, v. 17, n. 1, p. 40-47, jan./abr. 2013.

PLETSCH, M.D. A formação de professores para a educação inclusiva: legislação, diretrizes políticas e resultados de pesquisas. Educar em Revista. n.33. Curitiba, 2009.

POKER, R. B.; VALENTIM, F. O. D.; GARLA, I. A. Inclusão escolar e formação inicial de professores: a percepção de alunos egressos de um curso de Pedagogia. Revista Eletrônica de Educação, v.11, n.3, p.876-889, set./dez., 2017. 
RIBEIRO, R. R. R. P. C. Formação de professores para a educação inclusiva no contexto da legislação dos documentos oficiais: quais as mudanças concorridas. Dissertação (mestrado) - Universidade Estadual do Ceará, Centro de Educação, Curso de Mestrado Acadêmico em Educação, Fortaleza, 2012.

SAVIANI, D. Formação de professores: aspectos históricos e teóricos do problema no contexto brasileiro. Revista Brasileira de Educação v. 14 n. 40 jan./abr. 2009.

Recebido em: 19 de março de 2020

Aprovado em: 27 de julho de 2020

Publicado em: 17 de setembro de 2020 


\section{APÊNDICE A - TERMO DE CONSENTIMENTO LIVRE E ESCLARECIDO \\ UNIVERSIDADE FEDERAL DA BAHIA - UFBA \\ FACULDADE DE EDUCAÇÃO}

Título da Pesquisa: FORMAÇÃO DE PROFESSORES NO CURSO DE PEDAGOGIA DA UFBA E A ATUAÇÃO DOCENTE NA PERSPECTIVA INCLUSIVA.

Pesquisadoras Responsáveis: Profa. Dra. Sheila de Quadros Uzêda, (sheilauzeda@ufba.br) e Profa. Dra. Regiane da Silva Barbosa (regiane.barbosa@ufba.br).

1. Natureza da pesquisa: você está sendo convidada (o) a participar desta pesquisa que tem como finalidade investigar discutir a formação de professores no curso de pedagogia da UFBA para atuar com estudantes PAEE.

2. Envolvimento na pesquisa: ao participar deste estudo você permitirá que $\circ$ (a) pesquisadora colete dados a partir de questionário. Você tem liberdade de se recusar a participar desta pesquisa em qualquer fase, sem prejuízo para si. Sempre que quiser poderá pedir mais informações sobre a pesquisa através do telefone do (a) pesquisador (a).

3. Riscos: a participação nesta pesquisa não infringe as normas legais e éticas e, portanto, não há riscos nem benefícios diretos a você. Os procedimentos adotados nesta pesquisa obedecem aos Critérios da Ética em Pesquisa com Seres Humanos conforme Resolução no. 196/96 do Conselho Nacional de Saúde. Nenhum dos procedimentos usados oferece riscos à sua dignidade.

4. Benefícios: ao participar desta pesquisa você não terá nenhum benefício direto. Entretanto, esperamos que este estudo traga contribuições importantes sobre a formação docente e o processo de inclusão de estudantes PAEE no ensino regular

5. Sigilo: Os pesquisadores se comprometem a divulgar os resultados obtidos, em eventos de cunho científico e acadêmico, respeitando-se o sigilo das informações coletadas. Somente os pesquisadores terão conhecimento de sua identidade e nos comprometemos a mantê-la em sigilo ao publicar os resultados dessa pesquisa.

6. Pagamento: você não terá nenhum tipo de despesa para participar desta pesquisa, bem como nada será pago por sua participação.

Após estes esclarecimentos, solicitamos o seu consentimento de forma livre:

Eu, de forma livre e esclarecida, manifesto meu consentimento em participar da pesquisa e autorizo a divulgação dos dados obtidos neste estudo.

Assinatura do Participante da Pesquisa

Assinatura do Pesquisador 